\title{
Fluorouracil/Medroxyprogesterone/Melphalan Regimen
}

National Cancer Institute

\section{Source}

National Cancer Institute. Fluorouracil/Medroxyprogesterone/Melphalan Regimen. NCI

Thesaurus. Code C161981.

A chemotherapy regimen consisting of fluorouracil, melphalan, and

medroxyprogesterone acetate that may be used in the treatment of advanced or recurrent endometrial cancer. 